\title{
Expression of Type 2 lodothyronine Deiodinase in Hypothyroid Rat Brain Indicates an Important Role of Thyroid Hormone in the Development of Specific Primary Sensory Systems
}

\author{
Ana Guadaño-Ferraz, ${ }^{1}$ Maria José Escámez, ${ }^{1}$ Estrella Rausell, ${ }^{2}$ and Juan Bernal ${ }^{1}$ \\ 1/nstituto de Investigaciones Biomédicas "Alberto Sols," Consejo Superior de Investigaciones Cientificas-Universidad \\ Autónoma, and 2Departamento de Morfología, Universidad Autónoma de Madrid, Madrid, Spain
}

Thyroid hormone is an important epigenetic factor in brain development, acting by modulating rates of gene expression. The active form of thyroid hormone, 3,5,3'-triiodothyronine (T3) is produced in part by the thyroid gland but also after $5^{\prime}$ deiodination of thyroxine (T4) in target tissues. In brain, 80\% of T3 is formed locally from T4 through the activity of the 5 '-deiodinase type 2 (D2), an enzyme that is expressed mostly by glial cells, tanycytes in the third ventricle, and astrocytes throughout the brain. D2 activity is an important point of control of thyroid hormone action because it increases in situations of low T4, thus preserving brain T3 concentrations. In this work, we have studied the expression of D2 by quantitative in situ hybridization in hypothyroid animals during postnatal development. Our hypothesis was that those regions that are most dependent on thyroid hormone should present selective increases of D2 as a protection against hypothyroidism. D2 mRNA concentration was increased severalfold over normal levels in relay nuclei and cortical targets of the primary somatosensory and auditory pathways. The results suggest that these pathways are specifically protected against thyroid failure and that T3 has a role in the development of these structures. At the cellular level, expression was observed mainly in glial cells, although some interneurons of the cerebral cortex were also labeled. Therefore, the T3 target cells, mostly neurons, are dependent on local astrocytes for T3 supply.

Key words: thyroid hormones; deiodinases; astrocytes; barrel field; somatosensory system; auditory system; thalamus
Thyroid hormone [thyroxine (T4); 3,5,3'-triiodothyronine (T3)] is essential for maturation and function of the mammalian CNS (Legrand, 1984; Porterfield and Hendrich, 1993). Thyroid hormone deficiency during critical periods of development leads to cretinism, a syndrome characterized by severe anatomical and functional abnormalities, including mental retardation, deafness, and gait disturbances. Adult onset hypothyroidism or hyperthyroidism often impairs cognitive function and results in mood disturbances (DeGroot et al., 1984). The active hormone T3 binds to nuclear receptors that function as ligand-modulated transcription factors and regulate patterns of gene expression (Muñoz and Bernal, 1997; Oppenheimer and Schwartz, 1997).

$\mathrm{T} 3$ receptors are expressed in the rat brain in defined temporal and regional patterns (Mellström et al., 1991; Bradley et al., 1992), mainly in neurons and oligodendrocytes, whereas astrocytes in vivo express low levels of receptor (Carlson et al., 1994, 1996). A number of neuronal and oligodendrocyte genes are regulated by thyroid hormone, some of them directly at the transcriptional level (Bernal and Guadaño-Ferraz, 1998). The

\footnotetext{
Received Sept. 4, 1998; revised Feb. 16, 1999; accepted Feb. 18, 1999.

This work was supported by grants from the Fundación Ramón Areces, Comision Interministerial de Ciencia y Tecnologia Grants PM95-0019 and SAF-0031, and Comunidad de Madrid. We acknowledge Drs. Javier de Felipe and Carlos Avendaño for helpful discussions and interpretation of results, Drs. Reinoso-Suarez and Perez Marquez for their valuable help in the preparation of the figures, Fernando Nuñez and Pablo Señor for the care of animals, Maria Teresa Fernandez for art work, and Gloria Chacón for technical help.

A.G.-F. is the recipient of a contract, and M.J.E. is the recipient of a predoctoral fellowship from the Ministry of Education and Culture, and both have contributed equally.

Correspondence should be addressed to Dr. Juan Bernal, Instituto de Investigaciones Biomédicas, Arturo Duperier 4, 28029 Madrid, Spain.

Copyright (C) 1999 Society for Neuroscience $0270-6474 / 99 / 193430-10 \$ 05.00 / 0$
}

main determinants of thyroid hormone action are the number of receptor molecules per cell nucleus and the concentration of the active hormone $\mathrm{T} 3$. The mechanisms regulating regional brain $\mathrm{T} 3$ concentrations are not entirely understood. However, an important point of control is the expression and activity of deiodinases, enzymes that catalyze the removal of an iodine atom in the $5^{\prime}$ position of the T4 molecule (outer ring deiodinases, D1 and D2), thus resulting in the generation of $\mathrm{T} 3$, or in the 5 position of the T4 or T3 molecule (inner ring deiodinase, D3), generating the inactive metabolites reverse $\mathrm{T} 3$ (3,3',5'-triiodothyronine) or T2 (3,3'-diiodothyronine), respectively (St. Germain, 1994; St. Germain and Galton, 1997). Control of local brain generation of T3 is of high physiological significance because $\sim 80 \%$ of T3 in this organ is produced locally through D2 activity (Crantz et al., 1982).

We have recently reported that $\mathrm{D} 2 \mathrm{mRNA}$ is located in glial cells, astrocytes in a number of brain regions, and in the tanycytes lining the lower part of the third ventricle (Guadaño-Ferraz et al., 1997b). Expression of D2 in glia suggested that these cells take up T4 from the circulation and generate T3, which could then be supplied to the neuronal targets. Expression of D2 is an important protective mechanism against hypothyroidism because the activity of the enzyme and the concentrations of the mRNA are elevated in situations of low T4, thus increasing the efficiency of T3 production (Silva and Mathews, 1984; Silva et al., 1984; Calvo et al., 1990; Obregón et al., 1991; Croteau et al., 1996). This protective mechanism is likely to be operating more efficiently, specifically in those neural systems critically dependent on thyroid hormone. Therefore, we have studied regional responses of D2 mRNA after neonatal hypothyroidism with the goal of identifying brain regions preferentially protected from thyroid hormone 
deprivation. The results suggest a previously unsuspected important role of thyroid hormone in the development and/or function of primary sensory systems.

\section{MATERIALS AND METHODS}

Animals and treatments. Wistar rats were used in these studies. The European Union (directive 609) guidelines for the care and handling of animals were followed. Severe hypothyroidism was induced using protocols previously described (Iñiguez et al., 1996). Briefly, pregnant dams were given $0.02 \%$ of the antithyroid drug 2-mercapto-1-methylimidazole (MMI; Sigma, St. Louis, MO) in the drinking water ad libitum from gestational day 10. The neonates were surgically thyroidectomized at postnatal day 5 (P5) while the mothers continued drinking the MMI solution. This protocol causes severe hypothyroidism, as shown by reduced growth rate and large decreases of T4 and T3 concentrations in serum and cerebral cortex. The administration of $\mathrm{T} 3$ to hypothyroid animals was performed as a single intraperitoneal dose of $50 \mu \mathrm{g} / \mathrm{rat} 24 \mathrm{hr}$ before killing.

Tissue processing. Anesthesia was induced by pentobarbital (Abbott Laboratories, Abbot Park, IL; $4 \mathrm{mg} / 100 \mathrm{gm}$ of body weight), and the animals were perfused transcardially with $4 \%$ paraformaldehyde in $0.1 \mathrm{M}$ phosphate buffer, $\mathrm{pH}$ 7.4. Brains were dissected out and post-fixed in the same solution for $12 \mathrm{hr}$ and cryoprotected at $4^{\circ} \mathrm{C}$ for $2-3 \mathrm{~d}$ in the paraformaldehyde solution containing $30 \%$ sucrose. They were then frozen in dry ice, and $25-\mu \mathrm{m}$-thick coronal sections were obtained in a cryostat. The sections were stored at $-70^{\circ} \mathrm{C}$ in a cryoprotectant solution containing $30 \%$ ethylene glycol and $30 \%$ glycerol in $0.1 \mathrm{M}$ phosphate buffer.

In situ hybridization histochemistry and immunohistochemistry. In situ hybridization for the detection of D2 mRNA was performed on freefloating sections according to protocols previously described in detail (Iñiguez et al., 1996). In summary, specific D2 sense (T7 RNA polymerase) and antisense (Sp6 RNA polymerase) riboprobes were synthesized in the presence of $\left[{ }^{35}\right.$ S]UTP using a 366 bp DNA template spanning nucleotides 535-901 from the rat D2 cDNA sequence (Croteau et al., 1996) and used as described (Guadaño-Ferraz et al., 1997b).

The free-floating sections from each animal were post-fixed in $4 \%$ paraformaldehyde, treated with $0.1 \%$ Triton X-100 in PBS, deproteinized with $0.2 \mathrm{~N} \mathrm{HCl}(10 \mathrm{~min})$, acetylated with $0.25 \%$ acetic anhydride in $0.1 \mathrm{M}$ triethanolamine buffer, $\mathrm{pH} 8.0$ (10 min), and washed in PBS. Prehybridization was performed at $55^{\circ} \mathrm{C}$ for $3-5 \mathrm{hr}$, in a solution containing $50 \%$ formamide, $10 \%$ dextran sulfate, $5 \times$ Denhardt's solution, $0.62 \mathrm{M} \mathrm{NaCl}, 50 \mathrm{~mm}$ DTT, 0.01 м EDTA, 0.02 м PIPES, pH 6.8, 0.2\% SDS, $250 \mu \mathrm{g} / \mathrm{ml}$ salmon sperm DNA, and $250 \mu \mathrm{g} / \mathrm{ml}$ yeast tRNA. Hybridization was performed in this solution at $55^{\circ} \mathrm{C}$ for $16 \mathrm{hr}$, with ${ }^{35} \mathrm{~S}$-labeled riboprobes at $2 \times 10^{7} \mathrm{cpm} / \mathrm{ml}$. Excess probe was removed with $2 \times$ SSC containing $10 \mathrm{~mm} \beta$-mercaptoethanol at room temperature for $30 \mathrm{~min}$, followed by incubation with $4 \mu \mathrm{g} / \mathrm{ml} \mathrm{RNase} A$ in $0.5 \mathrm{M} \mathrm{NaCl}$, $0.05 \mathrm{~m}$ EDTA, $0.05 \mathrm{M}$ Tris-HCl, pH 7.5, at $37^{\circ} \mathrm{C}$ for $1 \mathrm{hr}$. Stringency washes were performed in $0.5 \times \mathrm{SSC}(1 \times \mathrm{SSC}$ is $0.015 \mathrm{M} \mathrm{NaCl}$ and 0.0015 M Na citrate), $50 \%$ formamide, $10 \mathrm{~mm} \beta$-mercaptoethanol at $55^{\circ} \mathrm{C}$ for 2 $\mathrm{hr}$, and then in $0.1 \times \mathrm{SSC}$ and $10 \mathrm{~mm} \beta$-mercaptoethanol at $68^{\circ} \mathrm{C}$ for $1 \mathrm{hr}$.

To analyze the cell types that express D2 mRNA, a combination of in situ hybridization histochemistry and immunohistochemistry was performed on the same tissue section, using a double-labeling technique previously described elsewhere (Guadaño-Ferraz et al., 1997a,b). Briefly, after hybridization and washes, the free-floating sections were incubated sequentially with the primary antibody overnight at $4^{\circ} \mathrm{C}$ and then with a biotinylated secondary antibody (1:200; Vector Laboratories, Burlingame, CA) for $1 \mathrm{hr}$ at $4^{\circ} \mathrm{C}$, followed by ABC (Elite kit; Vector Laboratories). Peroxidase was then visualized with diaminobenzidine $(0.05 \%)$ and $\mathrm{H}_{2} \mathrm{O}_{2}$. Monoclonal antibodies (Sigma) against the $27 \mathrm{kDa}$ calciumbinding protein, vitamin D-dependent calbindin (final dilution 1:4000) was used to localize subsets of cortical interneurons (DeFelipe, 1997). A polyclonal antibody against glial fibrillary acidic protein (GFAP) (Dakopatts, Copenhagen, Denmark; final dilution 1:2000) was used to detect astrocytes. Omitting the primary antibody resulted in negligible color development.

In all cases, the sections were mounted on coated slides, air-dried, and exposed to Hyperfilm $\beta$-max (Amersham International, Buckinghamshire, UK) for 3 or 4 weeks, depending on whether the signal obtained was used for quantification or for delimiting cytoarchitectonic areas, respectively. For cellular resolution, the sections were dipped in Hypercoat LM-1 photographic emulsion (Amersham), exposed for 1 month in the cold, developed with D19, fixed, dehydrated, and coverslipped. When only in situ hybridization was performed, the sections were counterstained with either Richardson's blue or cresyl violet. Optical observations were made in a Zeiss Axiophot microscope (Carl Zeiss, Oberkochen, Germany).

Cytoarchitectonic studies. The autoradiographic films were scanned in a Nikon Coolscan II slide scanner (Nikon Corporation, Tokyo, Japan) at a resolution of 300 pixels/inch and printed. Series of adjacent sections to those processed for in situ hybridization were stained with cresyl violet, and an atlas of each brain was made by drawing outlines of all cytoarchitectonic borders. This step was of special relevance because there are not available data about the general architectonics of the hypothyroid brains. The analysis of the regional distribution of D2 mRNA was performed by overlapping camera lucida outlines of the cytoarchitectonic nuclei with the scaled prints. This information was put in register with the information provided by the observation, at high magnification and under bright- and dark-field illumination, of counterstained in situ hybridization sections. This task was assisted by computer graphics software that interfaced with a video camera attached to the microscope and with a slide scanner. For the identification of rat brain structures, we followed the descriptions by Jones (1985) and Swanson (1992).

Quantitative and statistical analysis. After film scanning, the autoradiographic signals were quantified using the NIH Image program, version 1.52 in a Macintosh computer (Apple Computer Inc., Cupertino, CA). Data are expressed as the optical density obtained from different brain regions after subtracting the film background. The value for each brain region of individual animals was recorded as the average of four measurements taken from three similar sections. A total of 11 animals at P15 were processed. Rats were divided into three experimental groups: control rats $(n=4)$, hypothyroid rats $(n=4)$, and hypothyroid, T3treated rats $(n=3)$. Additional P10 control rats $(n=2)$ were used. The final data were calculated from the average values of the animals used for each condition. The following regions were subjected to this analysis: lateral caudate putamen (LCP) and medial caudate putamen (MCP), layers I-III, IV, and VI of primary somatosensory cortex, medial and lateral divisions of the ventral posterior nuclei of the thalamus (VPM and VPL), medial geniculate complex (MG), and inferior colliculus (IC). Because of the heterogeneity of the signal (in hypothyroid and T3treated hypothyroid rats; Fig. 1), measurements in layer IV were restricted to the barrel field of the somatosensory cortex. Results were submitted to one-way ANOVA followed by the protected least significant difference post hoc test to identify statistically significant differences between groups (Snedecor and Cochran, 1980). Differences were considered significant when $p<0.05$.

\section{RESULTS}

\section{Regional distribution of $\mathbf{5}^{\prime}$-deiodinase type $\mathbf{2}$ mRNA}

The pattern of D2 expression was studied by in situ hybridization in the brains of normal and hypothyroid rats at $15 \mathrm{~d}$ of postnatal age. Around this time, peaks of T3 concentration and D2 activity occur, in coincidence with the time window for thyroid hormonedependent brain development (Kaplan and Yaskoski, 1981; Obregón et al., 1991). A group of hypothyroid rats was treated with a single high dose of T3 $24 \mathrm{hr}$ before killing to evaluate the acute response of D2 mRNA to hormone administration.

Film autoradiograms from representative coronal sections at different brain levels are shown in Figures 1 and 2. The results in normal control rats agree closely with our previous data (Guadaño-Ferraz et al., 1997b), with D2 mRNA expressed in the following areas (Figs. 1, 2, C panels): olfactory bulb (OB) and anterior olfactory nucleus (AON) (Fig. 1, top C panel); cerebral neocortex (CTX) layers I-IV and VI, piriform cortex (PIR) and olfactory tubercle (OT), the caudate putamen (CP) and the dorsal portion of the lateral septal nucleus (LSd) (Fig. 1, middle $C$ panel ); the hippocampus, especially the molecular layer of the dentate gyrus (DGmo) (Fig. 1, bottom $C$ panel); the ventral cochlear nucleus (VCO), the principal sensory nucleus of the trigeminus (PrV), the superior olivary complex (SOC) and periolivary nuclei (POR), and the nucleus of the trapezoid body (NTB) (Fig. 2, bottom C panel). Much lower levels of expression 

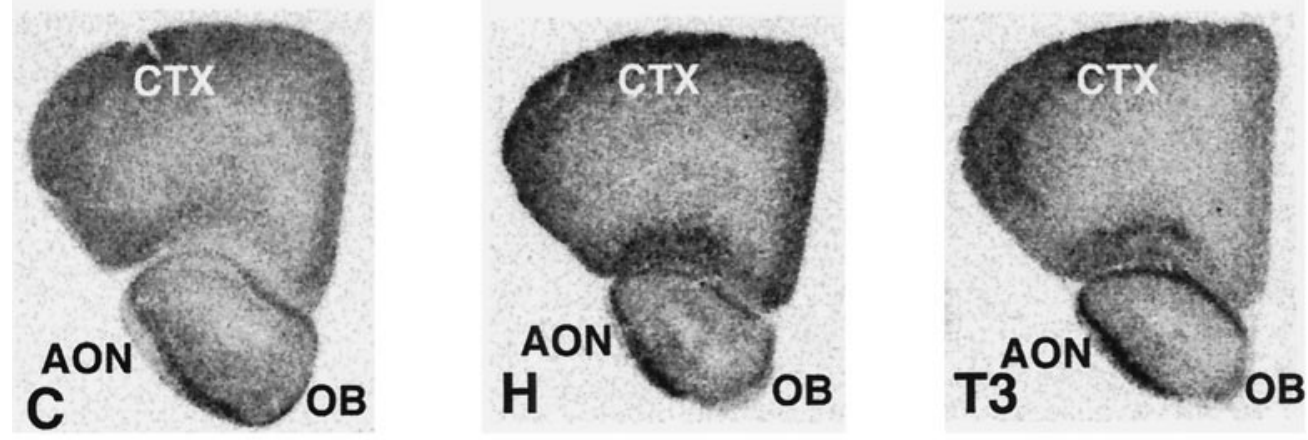

CB
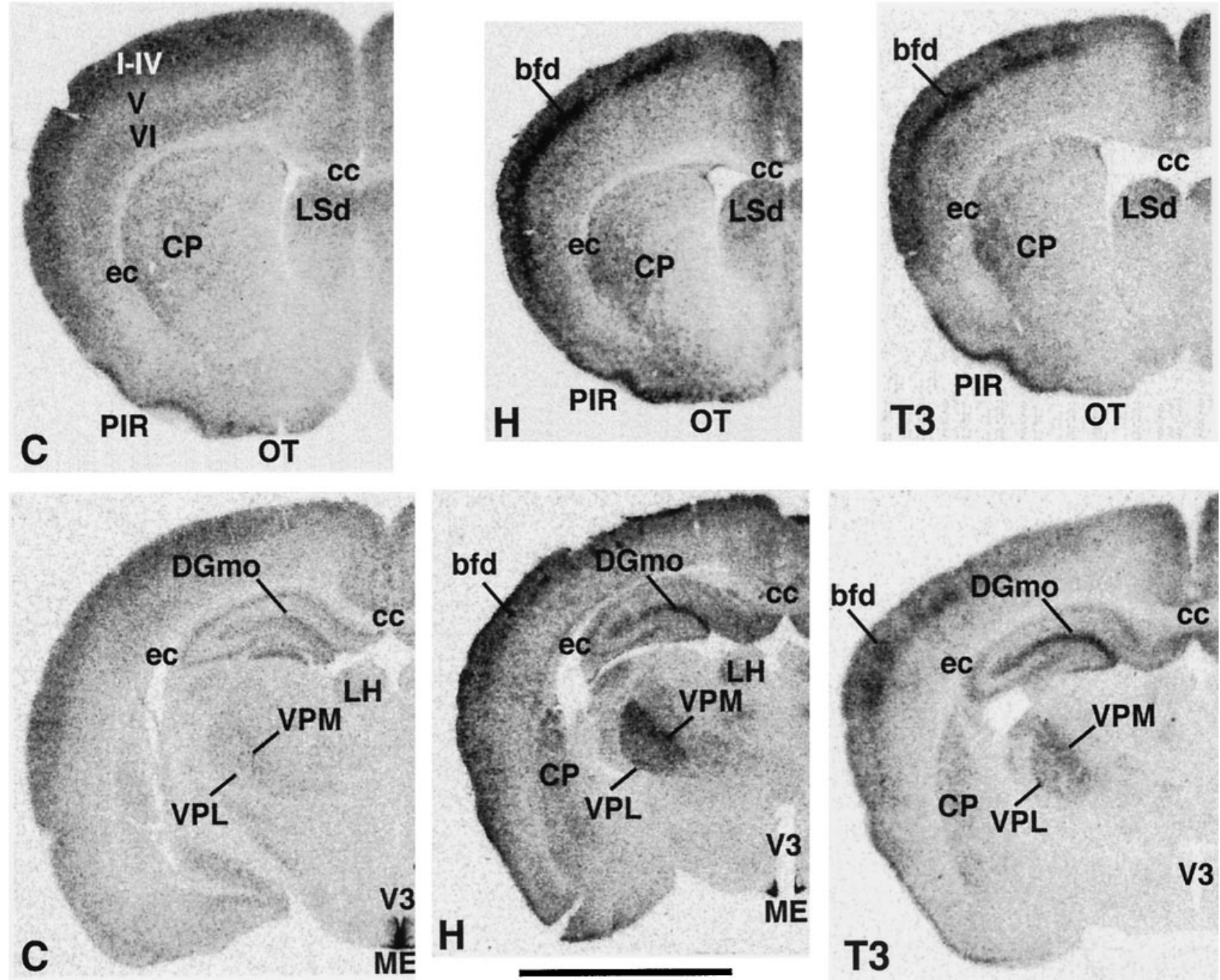

Figure 1. Expression of D2 transcripts in the brain of 15-d-old neonatal rats. C, Normal control rats (left panels); $H$, hypothyroid rats (middle panels); T3, T3-treated hypothyroid rats (right panels). Top right corner shows background hybridization when the sense RNA probe was used to hybridize hypothyroid slices. LH, Lateral habenula. Layers of the cerebral cortex are shown in roman numerals. Scale bar, $0.5 \mathrm{~cm}$.

were found in the VPL and VPM (Fig. 1, bottom $C$ panel), the $\mathrm{MG}$ and anterior pretectal region (APN) (Fig. 2, top $C$ panel), and the granular layer of the cerebellum (CB) (Fig. 2, bottom $C$ panel). As also described previously, the highest signal was present in the lateral aspects of the median eminence (ME) and the lining of the lower portion of the third ventricle (V3) (Fig. 1, bottom $C$ panel). Expression of D2 in this area has been shown to be caused by tanycytes, a specialized population of glial cells involved in the transport of hormones and other substances (Flament-Durand and Brion, 1985). There was no expression in areas of white matter, such as the corpus callosum (cc) and external capsule (ec; Fig. 1, middle and bottom $C$ panels). In contrast to hypothyroid animals (see below) only in overexposed autoradiograms from control animals, it was possible to detect a faint signal in areas such as the IC and the nucleus of the lateral lemniscus (NLL). 


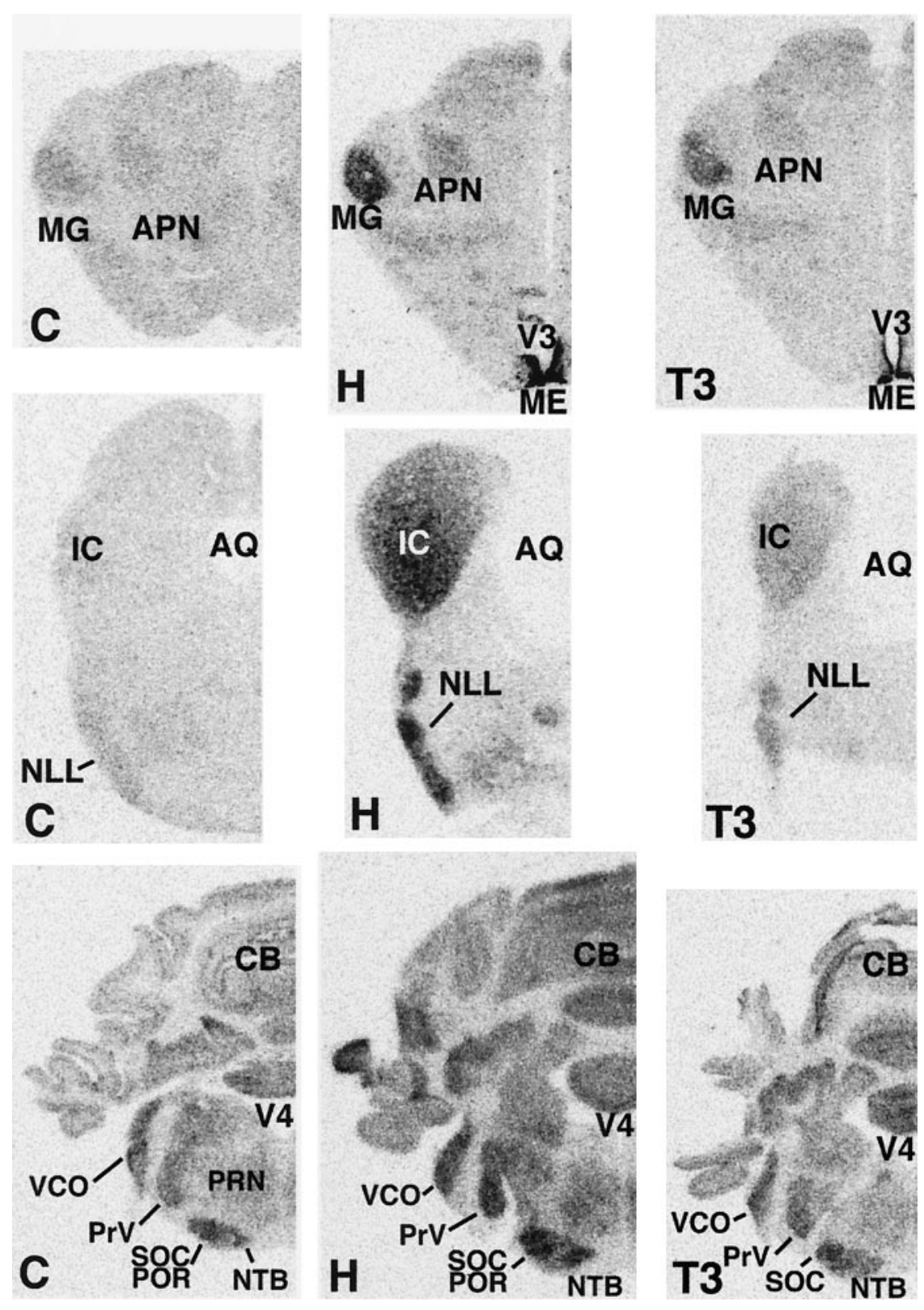

Figure 2. Expression of D2 transcripts in the brain of 15-d-old neonatal rats. $C$, Normal control rats (left panels); $H$, hypothyroid rats (middle panels); T3, T3treated hypothyroid rats (right panels). $A Q$, Cerebral aqueduct; $V 4$, fourth ventricle.
In hypothyroid rats (Figs. 1, 2, H panels), the general pattern of distribution of D2 mRNA was similar to the control rats, with the highest levels also present in the third ventricle/median eminence area. A clear increase in expression was found in the olfactory bulb and anterior olfactory nucleus (Fig. 1, top $H$ panel), the piriform cortex and the olfactory tubercle (Fig. 1, middle $H$ panel), the ventral posterior medial thalamic nucleus, the molecular layer of dentate gyrus (Fig. 1, bottom $\mathrm{H}$ panel), the medial geniculate nucleus (Fig. 2, top H panel), the inferior colliculus and nucleus of the lateral lemniscus (Fig. 2, middle $H$ panel), the ventral cochlear nucleus, principal trigeminal nucleus, superior olivary complex, periolivary nuclei, and the nucleus of trapezoid body (Fig. 2, bottom H panel). There was also an increase in the signal in layer IV presumably associated with the barrel field (bfd) of the somatosensory cortex and with the stripes of the auditory cortex (Fig. 1, middle and bottom H panels). Moderate increments in expression were observed in the lateral caudate (Fig. 1, middle and bottom $H$ panels), lateral septal nucleus (Fig. 1, middle $H$ panel), ventral posterior lateral thalamic nucleus (Fig. 1, bottom $H$ panel), the pretectal region (Fig. 2, top $H$ panel), and granular layer of cerebellum (Fig. 2, bottom H panel). Again, no expression was found in areas of white matter, such as the corpus callosum and external commissure. The use of a sense riboprobe resulted in a lack of hybridization signal (Fig. 1, top right corner).

Treatment of hypothyroid rats with a single dose of T3 (Figs. 1, 2, T3 panels) resulted in a pattern of D2 mRNA expression that was generally similar to that of hypothyroid animals. However, in some regions a decrease in the intensity of the signal was recorded. These include the ventral posterior lateral thalamic nucleus (Fig. 1), the medial geniculate complex, the pretectal region, the inferior colliculus, and the nucleus of lateral lemniscus (Fig. 2).

\section{Quantitative changes of D2 mRNA concentrations after modification of the thyroidal status}

To more accurately define regional changes in mRNA concentration after modification of the thyroid status, data from the differ- 
Figure 3. Concentration of D2 transcripts in selected regions of the brain of normal control rats (open bars), hypothyroid rats (gray bars), and hypothyroid rats treated with a single dose of T3 (black bars). After in situ hybridization the autoradiographic films were scanned, and the optical density of each region was measured using the NIH Image program. Data are mean \pm SEM of values from three rats per group. Levels of statistical significance are shown by asterisks: ${ }^{*} p<$ $0.05 ; * * p<0.01 ; * * *<<0.001 ; n s$, nonsignificant. Comparisons between the groups were made as shown by the horizontal lines above the bars. I-III, IV, V-VI, Cortical layers of the primary somatosensory area.

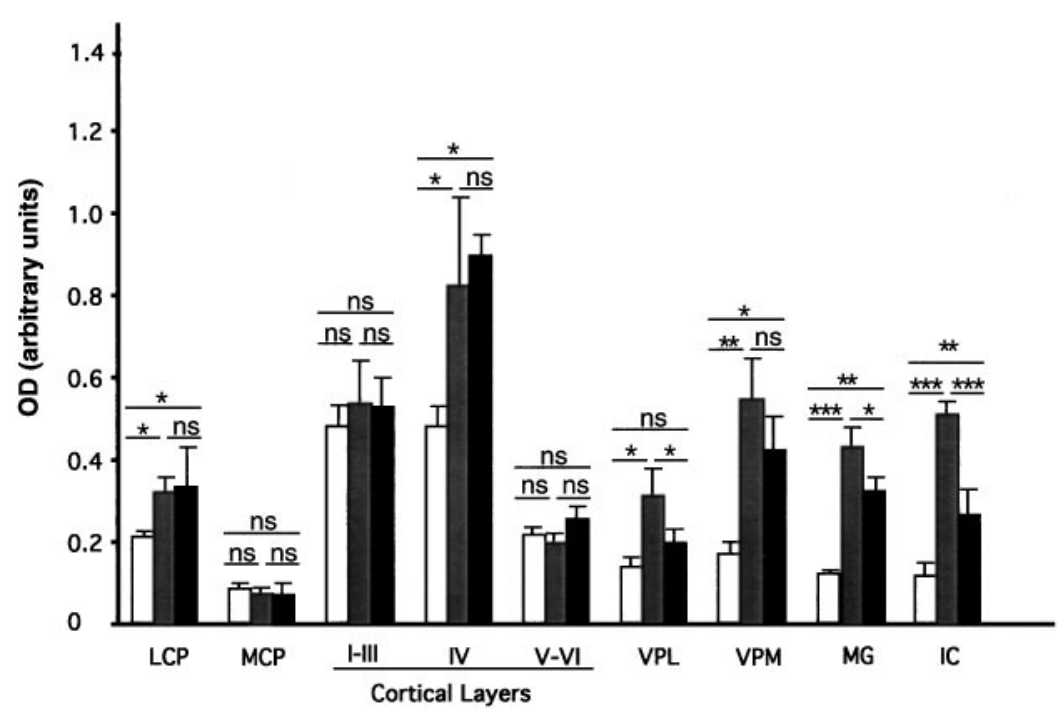

ent experimental groups were quantified as explained in Materials and Methods. The results are illustrated in Figure 3. Compared to normal rats (open bars), the increased signal in the autoradiograms illustrated in Figures 1 and 2 in hypothyroid rats (gray bars) was statistically significant in several regions, with a maximal effect in the inferior colliculus $(4.7 \pm 1.5$-fold; $p<$ $0.001)$, medial geniculate nucleus (3.6 \pm 0.3 -fold; $p<0.001$ ), and ventral posterior medial nucleus $(3.3 \pm 0.3$-fold; $p<0.01)$. No significant differences were recorded in the medial caudate and in cortical layers I-III and VI in the primary somatosensory area, whereas moderate increases occurred in the ventral posterior lateral nucleus (2.2 \pm 0.3 -fold; $p<0.05)$, layer IV $(1.7 \pm 0.3$-fold; $p<0.05)$, and lateral caudate $(1.5 \pm 0.2$-fold; $p<0.05)$. We also checked the possibility that $\mathrm{T} 3$ itself exerted a primary control on D2 expression by examining the effect of a single administration of a high dose of T3 to hypothyroid animals. In similar experiments, T3 was able to restore to normal levels the low levels of RC3/neurogranin mRNA present in hypothyroid animals (Guadaño-Ferraz et al., 1997a). In contrast, T3 had no effect on D2 mRNA in most of the regions analyzed, with the exception of the VPL, MG, and IC, where a decrease was recorded. These results suggest that the influence of thyroid hormone deprivation and administration on D2 mRNA are likely to be indirect effects, not mediated by a direct interaction of the $\mathrm{T} 3$ receptor with regulatory sequences of the D2 gene.

\section{High expression of D2 in sensory pathways of P15 hypothyroid rats}

The above results indicate that the strongest effects of hypothyroidism on D2 mRNA concentration occurred in areas related to the primary sensorium, namely the trigeminal and auditory pathways. This fact was assessed by analyzing in detail full series of sections all through the brain, matching D2 autoradiographic signals with Nissl stains of the same and adjacent slices.

In the somatosensory system, the D2 mRNA hybridization signal was consistently increased in all the synaptic stations of the lemniscal and spinothalamic pathway, especially in the trigeminal component, all the way to the somatosensory cortex. In the lemniscal pathway, the signal was significantly high in the dorsal column nuclei: gracile (GR) and cuneate (CU; Fig. $\left.4 C, C^{\prime}\right)$ and in the $\operatorname{PrV}$ (Fig. $5 C, C^{\prime}$ ), as it was in their respective thalamic targets, VPL and VPM. The signal was consistently higher in VPM than in VPL (Fig. $4 B, B^{\prime}$ ), in parallel with what was observed in their cortical targets. In the somatosensory cortex, the signal was significantly stronger than in adjacent cortices being consistently concentrated in layers III-IV, forming patches that correlated in terms of their topology with the previously well defined cellular aggregations of the "barrel field" (Fig. $4 A$ ). The signal was mainly associated with the neuropil, but frequently silver grains formed accumulations with round shapes (Figs. $4 A b, 6 A, C$ ). High levels of sparsely distributed signal were found associated with layer I (Fig. 4Aa)

The analysis of the spinal-trigeminothalamic pathway revealed strong signal levels in all the synaptic stations: the spinal trigeminal complex (SpV; Fig. $\left.4 C, C^{\prime}\right)$, the thalamic posterior complex (PO; Fig. $4 B, B^{\prime}$ ), and in its cortical target, the interbarrel space within the barrel field. In the cortex, the radioactive signal in the interbarrel space was more sparsely distributed than within the barrels and less frequently concentrated in grain accumulations (Fig. 4A).

In the auditory system, D2 mRNA hybridization signal in hypothyroid brains was also consistently increased in a number of nuclei related to the auditory pathways up to the thalamus and cortex: the ventral and dorsal cochlear nuclei (DCO), SOC, POR, $\mathrm{NTB}, \mathrm{NLL}$, and the IC in the brainstem (see Fig. $5 B, B^{\prime}, C, C^{\prime}$ for all nuclei and Fig. 2, bottom row for $S O C$ and $P O R$ ). The MG in the thalamus (Fig. $5 A, A^{\prime}$ ) was strongly labeled. The radioactive signal found in all the subcortical somatosensory nuclei was not distributed homogeneously. It was rather associated with groups of neurons. For instance, in the VPM the silver grains grouped within and surrounding the "barreloids", whereas in other nuclei the distribution of silver grains paralleled their local cellular arrangement.

Qualitatively significant levels of D2 mRNA signal were also observed in isolated components of other systems. High levels of hybridization signal were consistently observed in visual primary sensory nuclei, like the ventral and dorsal parts of the lateral geniculate nucleus of the thalamus (Fig. $4 B, B^{\prime}, L G d, L G v$ ) and the APN (Figs. 2, top row, 5A, $A^{\prime}$ ). This was also true for the vestibular pathway, especially for the lateral vestibular nucleus (LV; Fig. $5 C, C^{\prime}$ ). The signal was also significantly stronger in a number of nuclei related with the activating ascending reticular pathway, like the thalamic reticular nucleus (RT; Fig. $4 B, B^{\prime}$ ) in 

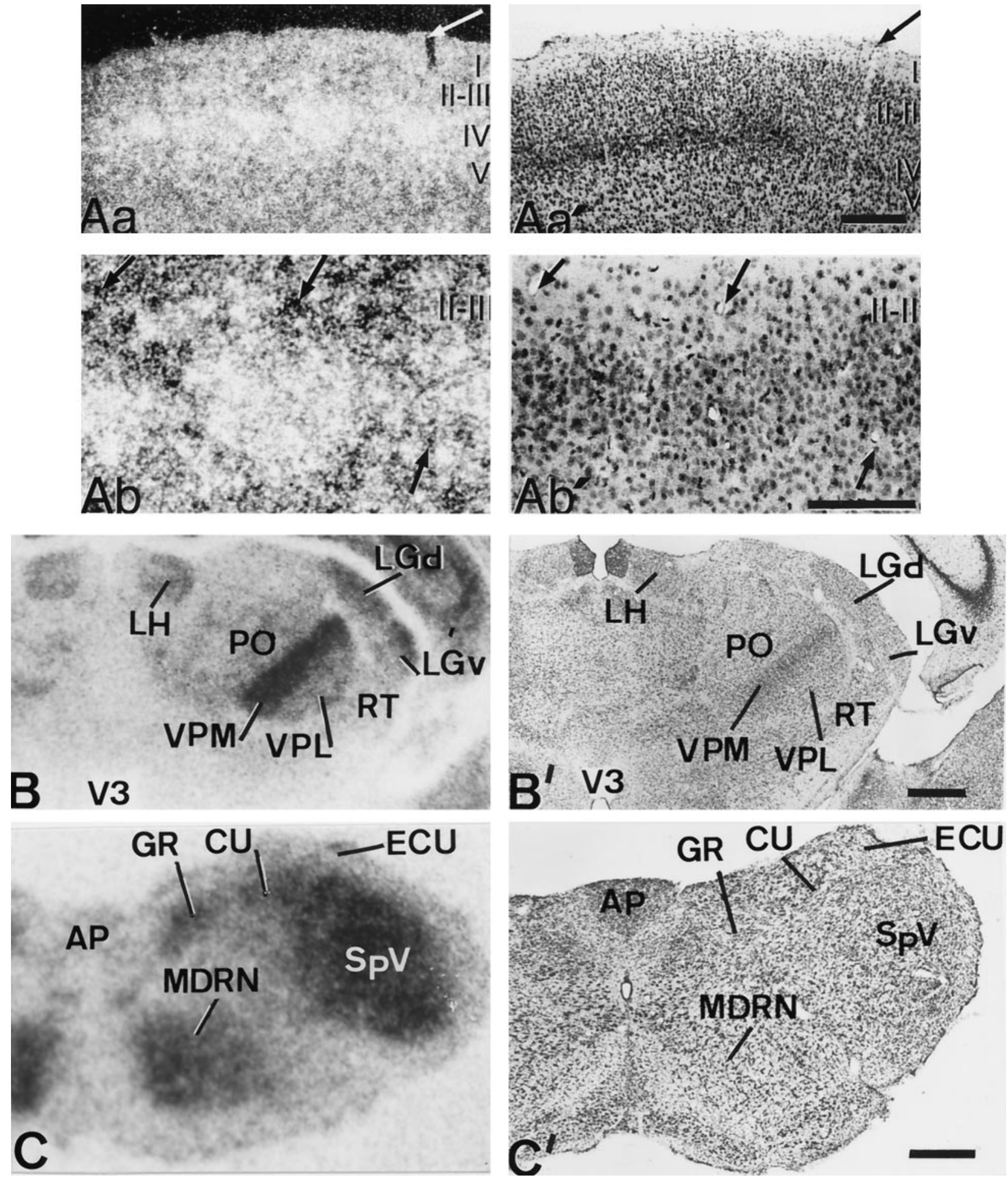

Figure 4. Patterns of D2 expression in the primary somatosensory pathways of hypothyroid rats. $A a$ is a dark-field, low-magnification photomicrograph of the somatosensory cortex taken from a hybridized section coated with photographic emulsion. Note that high intensity of signal is present in all the cortex but is especially high in the barrels of layer IV; $A a^{\prime}$ is the adjacent section, at the same magnification and bright-field illumination that had been processed as in $A a$, and was also counterstained with cresyl violet. The arrows point to adjacent cuts of the same vessel. The fact that the intensity of labeling is much higher within the barrels than in the interbarrel space is addressed at higher magnification in $A b$ and $A b^{\prime}$. $A b$ shows high concentration of silver grains within a barrel whose limits are defined by Nissl staining $\left(A b^{\prime}\right)$. Arrows point to the same vessels in both photomicrographs. $B, C$, Autoradiographs from coronal sections at the thalamic and medullar levels, respectively; $B^{\prime}, C^{\prime}$, the corresponding adjacent sections stained with cresyl violet. The highest signal is associated with relay nuclei of the lemniscal pathway, i.e., gracile and cuneate nuclei and VPM and VPL. A high-intensity signal is also associated with the spinothalamic pathway, i.e., SpV and PO. In both pathways, the trigeminal component has the strongest D2 mRNA expression. $A P$, Area postrema; $E C U$, external cuneate nucleus; $L G d$ and $L G v$, lateral geniculate nucleus of the thalamus, dorsal and ventral parts. Layers of the cerebral cortex are shown in roman numerals. Scale bars, $500 \mu \mathrm{m}$. 

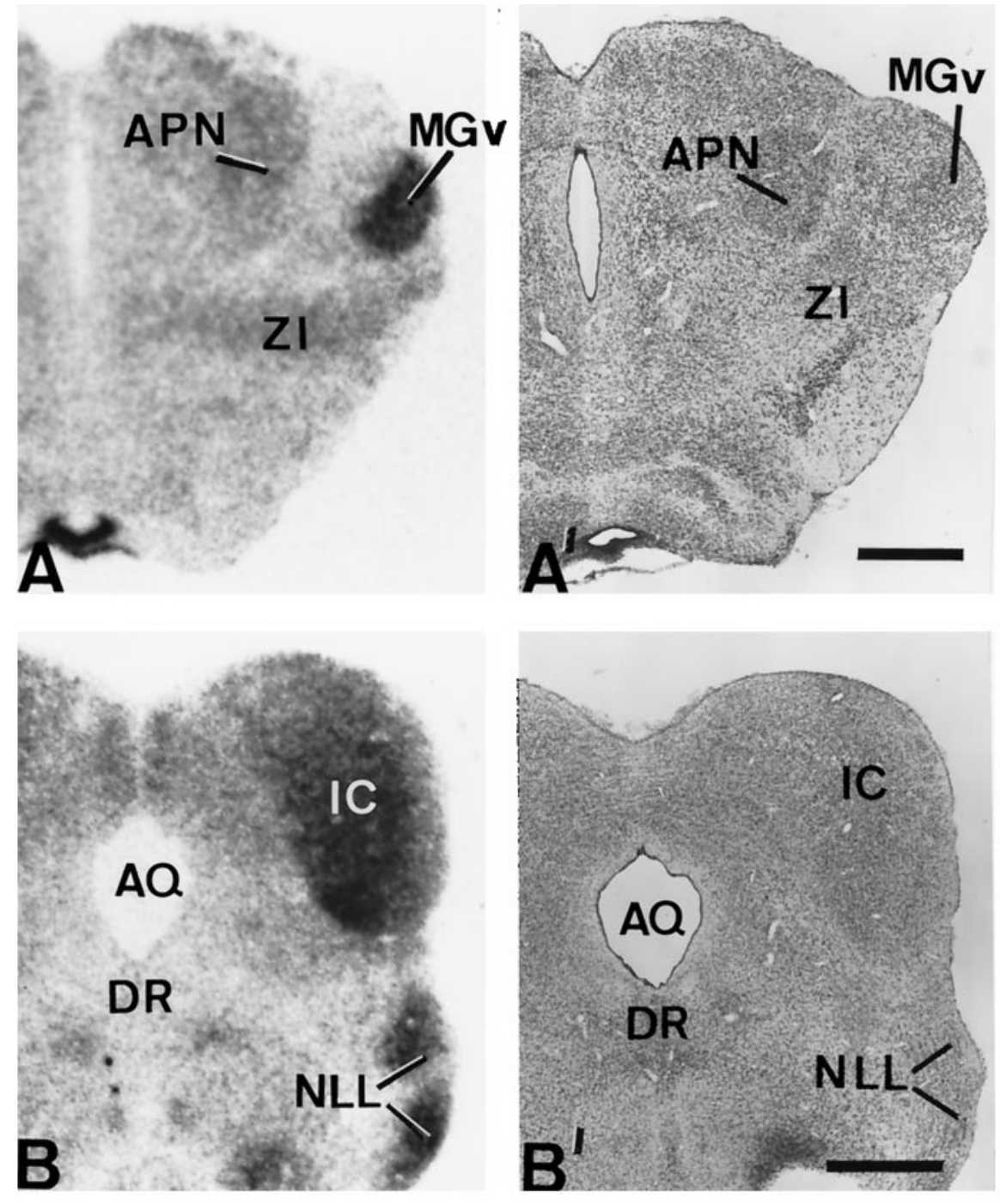

the auditory pathway of hypothyroid rats. The left side shows autoradiographs obtained from coronal sections of hypothyroid brains at thalamic $(A)$, mesencephalic $(B)$, and medullar $(C)$ levels subjected to in situ hybridization. Their corresponding adjacent sections stained with cresyl violet are shown on the right side $\left(A^{\prime}, B^{\prime}, C^{\prime}\right)$. Note the high levels of expression in relay nuclei of the auditory pathway, i.e., the medial geniculate nucleus, the inferior colliculus, the nucleus of the lateral lemniscus, and the dorsal and ventral cochlear nuclei. $D R$, Dorsal nucleus raphe; $M G v$, medial geniculate nucleus ventral part; $M V$, medial vestibular nucleus; ZI, zona incerta. Scale bars, $500 \mu \mathrm{m}$.
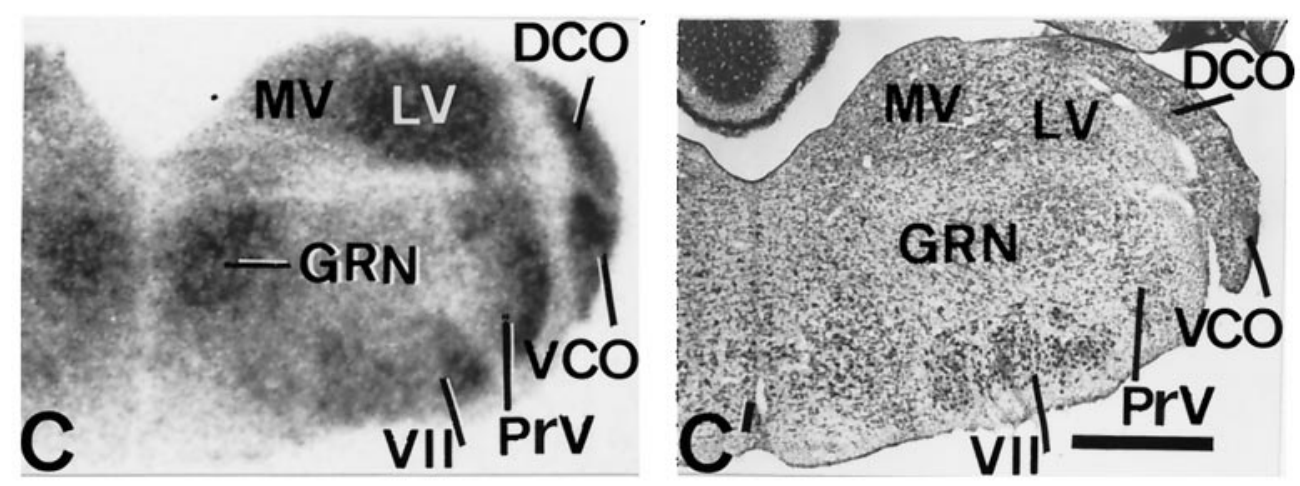

the diencephalon and the pontine reticular nucleus (PRN; Fig. 2, bottom row) in the brainstem. There was also high signal in nuclei related with the motor descending reticular pathway like the gigantocellular reticular nucleus (GRN; Fig. 5C, $C^{\prime}$ ) and the medullary reticular nucleus (MDRN; Fig. $4 C, C^{\prime}$ ) in the brainstem. Interestingly, the motor facial nucleus also contained high levels of hybridization signal (Fig. $5 C, C^{\prime}$ ).

To assess that the difference in the D2 mRNA expression in specific regions of hypothyroid rats was not caused by a delay in development, control rats at an earlier postnatal age (P10) were analyzed. Earlier ages were not used because some of the struc- tures analyzed at P15 are not completely developed in the normal rat, for example, the barrel field (Waite and Tracey, 1994). The results obtained showed that D2 expression in control P10 animals was qualitatively similar to control P15 rats (data not shown). Therefore, the D2 expression pattern displayed by P15 hypothyroid animals was not caused by delayed development and thus reflects a specific consequence of the lack of thyroid hormone.

\section{Cell types expressing D2 in hypothyroid rats}

As noted above, the increased content of D2 transcripts in hypothyroid brains was macroscopically associated with neuronal 


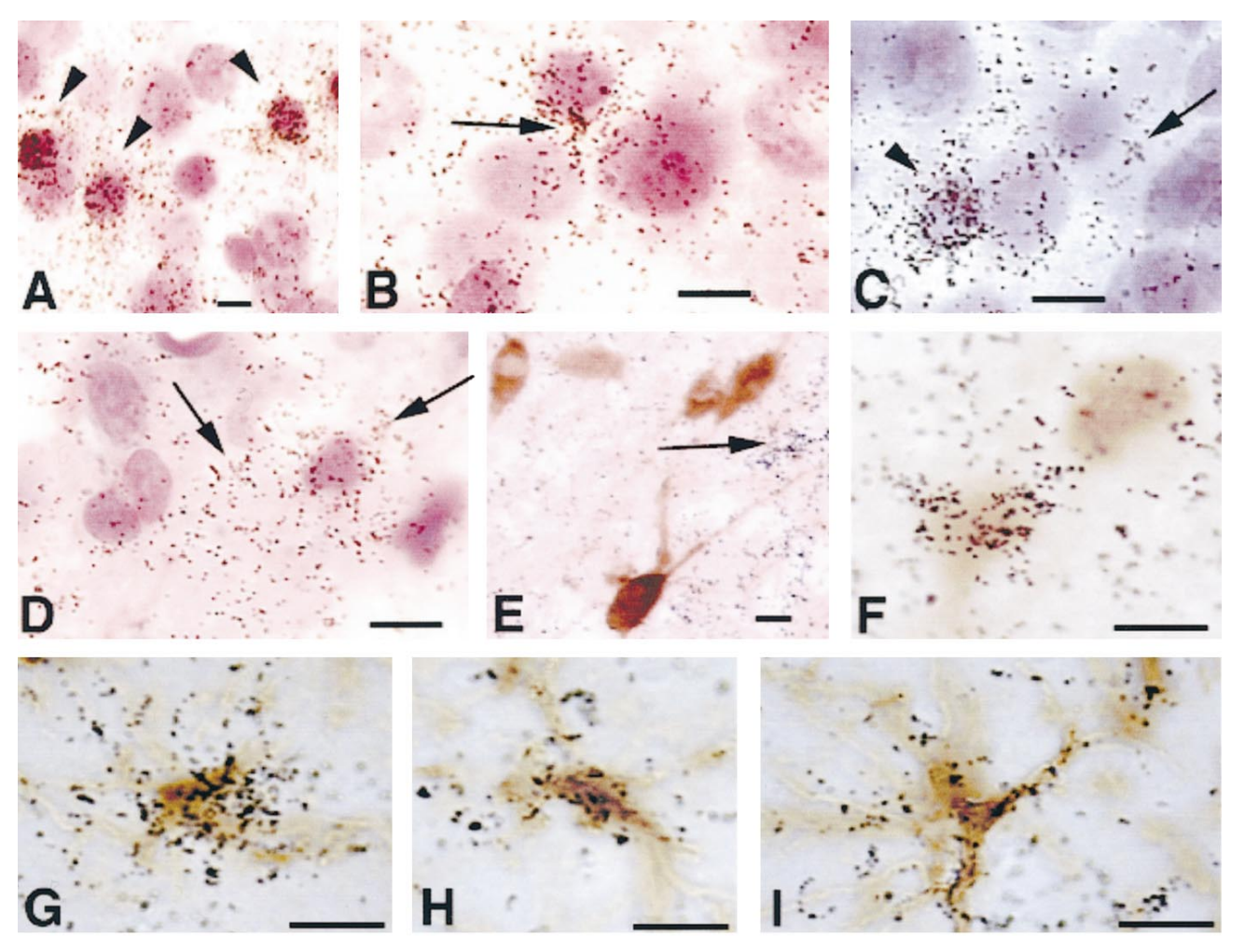

Figure 6. High-magnification photomicrographs taken from hypothyroid brain sections after in situ hybridization. The sections were either counterstained with cresyl violet $(A-D)$ or subjected to immunohistochemistry for calbindin $(E$, $F)$ or GFAP $(G-I)$. $A$, Barrel field of the somatosensory cortex; $B$, upper layer $\mathrm{IV}$; $C$, deep layer IV. Note that silver grains are concentrated within small neuronal profiles $(A, C$, arrowheads) and in the neuropil that surrounds larger neuronal profiles, resembling glial shapes $(B, C$, arrows). $D$, Photomicrograph taken from the core of ventral posterior medial nucleus. The concentration of silver grains is mainly in the neuropil that surrounds Nissl-stained nuclei. The arrows point to glial-like shapes. E, Several calbindin-positive, D2-negative cells photographed from layer II; D2 transcripts are distributed in the neuropil or in clusters resembling glial shapes (arrow). F, Two calbindinpositive cells photographed from laver IV of the barrel field, one of which is also positive for D2. $G-I$, Astrocytes from layer IV of the somatosensory cortex double-labeled for D2 by in situ hybridization and GFAP by immunohistochemistry. The silver grains are associated with the cell bodies and with the cell processes. Scale bars: $A-F, 10 \mu \mathrm{m}$; $G-I, 5 \mu \mathrm{m}$. groups. However, in a previous study using P15 normal rats we observed that, besides tanycytes, D2 mRNA was predominantly, if not exclusively, located in astrocytes (Guadaño-Ferraz et al., 1997b). It was important, therefore, to determine whether the increased D2 expression observed in hypothyroid rats was also taking place in glial cells. To this end, we performed emulsion autoradiography of D2 combined with either Nissl counterstaining (Fig. 6A-D) or immunohistochemistry for GFAP (Fig. 6G-I) or calbindin (Fig. $6 E, F)$.

Results in normal control rats were similar to those previously reported. Silver grains were located in association with astrocyte bodies but mostly with astrocytic processes. The concentration of silver grains in hypothyroid rats increased in specific brain regions as described above. Nissl staining after emulsion autoradiography showed that in all regions analyzed the radioactive signal was not observed lying over large neuronal nuclei, but it was distributed in their surrounding neuropil, and very frequently in association with small nuclei that resembled glial shapes. Within the cortical barrels (Fig. 6A-C), we frequently observed high concentration of grains associated with small nuclei that ranged $6-9 \mu \mathrm{m}$ in diameter and stained darkly with Nissl technique; silver grains were also observed in the surrounding neuropil at higher magnification, sometimes associated with very small nuclei $(<2 \mu \mathrm{m})$. D2 mRNA was not expressed in large ( $>10 \mu \mathrm{m}$ in diameter), lightly stained nuclei. These observations indicate that D2 was expressed in glial cells and in some interneurons, but not in pyramidal neurons. Using calbindin immunohistochemistry in association with in situ hybridization for D2, a small number of cells were positive for both D2 and calbindin in the granular layers of the somatosensory cortex, associated with the barrel field (Fig. $6 E, F)$. Parvalbumin could not be used as a marker because for unknown reasons it did not result in positive staining in P15 hypothyroid brains.
Expression of D2 by astrocytes was confirmed by performing D2 in situ hybridization with immunohistochemistry using antiGFAP. As previously reported (Guadaño-Ferraz et al., 1997b) in control brain sections, the majority of silver grains were found associated mainly with the cell processes, sometimes at a considerable distance from the cell body. In hypothyroid brains, including the barrels of the somatosensory cortex (Fig. 6G-I) there was a high concentration of grains associated with the cell bodies of astrocytes. In the midbrain nuclei, where the increased expression of D2 was highest (MG, IC, VPL, and VPM) the signal was absent from large neuronal profiles and was present either in the neuropil or associated with glial-like shapes (Fig. 6D). It was not possible to colocalize the signal with astrocytes because of extremely weak GFAP staining in these areas.

\section{DISCUSSION}

In this work we show that expression of D2 increases in somatosensory areas of the brain of postnatal rats after induction of hypothyroidism. These results suggest that these areas are specific targets for protection from the damage that the lack of thyroid hormone exerts on brain development. Expression of deiodinase type 2 is of great importance because in the brain most intracellular T3, the active form of thyroid hormone, is generated locally from its precursor T4 (Crantz et al., 1982). This enzyme contributes to maintain the brain concentrations of T3 under narrow margins, even in situations of wide changes in thyroid secretion and plasma thyroid hormone concentrations. In a rat model of congenital hypothyroidism with nonfunctioning maternal and fetal thyroids, Calvo et al. (1990) found that administration of T4, but not T3, to the mother was able to maintain normal T3 concentrations in the fetal brain. Also, under conditions of low iodine intake, the increased activity of D2 maintains normal brain $\mathrm{T} 3$ concentrations in the face of greatly reduced $\mathrm{T} 4$ 
concentrations in plasma and brain (van Doorn et al., 1982; Obregon et al., 1991). Decreased levels of cellular concentrations of T4 itself is considered to be partly responsible for the increased D2 activity because T4 inhibits D2 activity in cellular preparations through a posttranslational mechanism (Farwell et al., 1990). In the present work we show that in the intact animal, an additional mechanism operates at the pretranslational level, leading to increased concentration of D2 mRNA, in line with findings from other authors (Croteau et al., 1996; Burmeister et al., 1997; Tu et al., 1997; Diano et al., 1998).

In hypothyroid rats, the concentrations of D2 mRNA were relatively high in the relay nuclei of lemniscal and spinothalamic pathway, especially the trigeminal component, and in the auditory pathway. In some nuclei, such as the VPM, the IC and the MG expression in normal animals was very low and near background levels, whereas it was prominent in hypothyroid animals. In the cerebral cortex, hypothyroidism induces changes in the relative distribution of the label. Although D2 mRNA is diff usely distributed over layers I-IV in the normal brain, it becomes prominent in layer IV, specifically the barrel field, in hypothyroid animals. The pattern of D2 expression in hypothyroid P15 rats was different from that of normal P10 rats, suggesting that the effects of hypothyroidism on D2 expression were not caused by delayed development. The increased expression of D2 during a critical period of development in response to hypothyroidism reflects a protective mechanism aimed at maintaining normal brain $\mathrm{T} 3$ concentrations. It is reasonable to expect that this mechanism should operate more efficiently in regions where T3 is more needed during development. Therefore, the data are consistent with the idea that thyroid hormone has an important role in the postnatal development of the primary somatosensory and auditory systems.

The involvement of thyroid hormone in the auditory system was previously known because T3 is essential for normal cochlear development. Deafness is frequently present in congenital thyroid disorders (Forrest, 1996). The cochlea is one of the few organs in which a function can be attributed to a single T3 receptor isoform. Specifically, the T3 receptor $\beta$ isoform is expressed early during development of the inner ear (Bradley et al., 1994) and deletion of the gene in humans or knock-out mice results in deafness (Takeda et al., 1992; Forrest et al., 1996). In addition to its role in the cochlea, our results suggest that $\mathrm{T} 3$ is also required by the central auditory pathways. It is likely that T3 coordinates developmental processes all along the auditory pathway; however, no functional alterations have been observed in the brainstem of $\operatorname{TR} \beta$ knock-out mice (Forrest et al., 1996), which is probably because of redundancy in the expression of receptor isoforms. On the other hand, abnormalities of the auditory cortex in hypothyroid rats have been previously described, for example in the dendritic spine distribution of pyramidal cells (Ruiz Marcos et al., 1983), in the pattern of callosal connections (Berbel et al., 1993), and in the patterns of neuronal migration (Lucio et al., 1997). The involvement and role of $\mathrm{T} 3$ in the development and function of the somatosensory system is unknown and has not been studied specifically. As a bottom line of our results, it may be anticipated that extremely severe hypothyroidism, perhaps not compatible with life, should be induced to override the D2 protection mechanism and observe alterations induced by thyroid hormone deprivation. The role of thyroid hormone in these pathways should be studied in D2 knock-out mice rendered hypothyroid when they become available.

In normal rats D2 is expressed predominantly, if not exclusively, in glial cells (Guadaño-Ferraz et al., 1997b). In hypothy- roid animals, and according to the information provided by Nissl counterstaining of sections processed for in situ hybridization, D2 is also expressed in glial cells. Even the increased production of D2 mRNA in somesthetic and auditory pathways seemed to be associated with astrocytes in the brainstem, midbrain, and cerebral cortex. In those regions, most of the hybridization signal was lying over shapes that resembled astrocytic bodies or processes. No signal was present over typical (large nuclei) neuronal profiles and with few exceptions in the barrel cortex, most of the cortical autoradiographic signal did not colocalize with calbindin, a well known neuronal marker.

It was difficult in some cases to provide direct evidence about the astrocytic nature of these cells because of a number of technical reasons; among them, GFAP staining is low in regions with high increases of D2 hybridization, such as the midbrain nuclei. However, the information gathered with the doublelabeling experiments is consistent with Nissl findings and points toward the fact that the increase in D2 expression takes place in astrocytes. In the VPM, for instance, where a great increase of D2 mRNA was induced by hypothyroidism, the signal was associated with very small cellular profiles. Because the VPM of rodents does not contain interneurons, it is very likely that these profiles belong to glial cells. In the somatosensory cortex, however, the hybridization signal was found lying over two sets of cellular profiles. The most abundant were glial-like cells with very small nuclei, and less frequently larger profiles with sizes compatible with interneuronal nuclei. Double-labeling experiments resulted in colocalization of the radioactive signal with the GFAP immunochemical signal over the very small profiles confirming their astrocytic nature. The hybridization signal lying over the larger cells was often colocalized with calbindin. Taken together, these data suggest that hypothyroidism results in an increased D2 expression in glial cells where it is normally expressed in the P15 rat brain. In addition, the high expression of D2 in the somatosensory cortex of hypothyroid rats is not restricted to astrocytes, but also occurs in subsets of interneurons that do not produce detectable levels of D2 transcripts under normal control situations.

An important question that can be examined in light of our findings is whether the increased expression of D2 as a protective mechanism is the cause for the region-specific effects of thyroid hormone on gene expression. For example, the RC3/neurogranin gene, which is regulated directly by $\mathrm{T} 3$ at the level of transcription, is a target of the hormone only in discrete brain regions (Iñiguez et al., 1996; Guadaño-Ferraz et al., 1997a). It is possible that in areas that apparently are refractory to T3, despite expression of T3 receptors (upper layers of cortex, piriform cortex, medial geniculate nucleus), an increased expression of D2 might provide enough local T3 to maintain normal RC3 expression, although other mechanisms possibly involving nuclear receptor corregulators cannot be discarded.

The administration of T3 to hypothyroid animals failed to revert mRNA levels to normal in most regions, suggesting that T3 has no direct effects on the D2 gene. Therefore, the increased D2 mRNA observed in hypothyroidism likely represents an indirect consequence of $\mathrm{T} 3$ deprivation, distal to a primary effect of the hormone. Given that D2 appears to be expressed primarily in glial cells that contain few T3 receptors (Yokota et al., 1986; Puymirat et al., 1991; Leonard et al., 1994; Carlson et al., 1994, 1996) and not in neuronal cells, which are the classical thyroid hormone targets in the brain, we propose that regulation of D2 expression in astrocytes is mediated indirectly through an effect of thyroid hormone on neurons. It is conceivable that neurons 
sense a reduction of available T3 and then influence indirectly D2 expression in astrocytes. It will be important to identify the signals involved in this process. It is likely that they represent products of neuronal genes regulated at the genomic level by T3. In this respect, at least one of the T3-regulated neuronal genes, NCAM, mediates some of the actions that hormonal steroids exert on astrocytes (García-Segura et al., 1995).

\section{REFERENCES}

Berbel P, Guadaño-Ferraz A, Martínez M, Quiles JA, Balboa R, Innocenti GM (1993) Organization of auditory callosal connections in hypothyroid adult rats. Eur J Neurosci 5:1465-1478.

Bernal J, Guadaño-Ferraz A (1998) Thyroid hormones and the development of the brain. Curr Opin Endocrinol Diabetes 5:296-302.

Bradley DJ, Towle HC, Young III WS (1992) Spatial and temporal expression of $\alpha$ and $\beta$ thyroid hormone receptor mRNAs, including the $\beta 2$-subtype, in the developing mammalian nervous system. J Neurosci 12:2288-2302.

Bradley DJ, Towle HC, Young III WS (1994) $\alpha$ and $\beta$ thyroid hormone receptor (TR) gene expression during auditory neurogenesis: evidence for TR isoform-specific transcriptional regulation in vivo. Proc Natl Acad Sci USA 91:439-443.

Burmeister LA, Pachucki J, St. Germain DL (1997) Thyroid hormones inhibit type 2 iodothyronine deiodinase in the rat cerebral cortex by both pre- and posttranslational mechanisms. Endocrinology 138:5231-5237.

Calvo R, Obregón MJ, Ruiz de Oña C, Escobar Del Rey F, Morreale De Escobar G (1990) Congenital hypothyroidism, as studied in rats: crucial role of maternal thyroxine, but not 3,5,3'-triiodothyronine in the protection of the fetal brain. J Clin Invest 86:889-899.

Carlson DJ, Strait KA, Schwartz HL, Oppenheimer JH (1994) Immunofluorescent localization of thyroid hormone receptor isoforms in glial cells of rat brain. Endocrinology 135:1831-1836.

Carlson DJ, Strait KA, Schwartz HL, Oppenheimer JH (1996) Thyroid hormone receptor isoform content in cultured type 1 and type 2 astrocytes. Endocrinology 137:911-917.

Crantz FR, Silva JE, Larsen PR (1982) An analysis of the sources and quantity of 3,5,3'-triiodothyronine specifically bound to nuclear receptors in rat cerebral cortex and cerebellum. Endocrinology 110:367-375.

Croteau W, Davey JC, Galton VA, St. Germain DL (1996) Cloning of the mammalian Type II iodothyronine deiodinase. A selenoprotein differentially expressed and regulated in human and rat brain and other tissues. J Clin Invest 98:405-417.

DeFelipe J (1997) Types of neurons, synaptic connections and chemical characteristics of cells immunoreactive for calbindin-D28K, parvalbumin and calretinin in the neocortex. J Chem Neuroanat 14:1-19.

DeGroot LJ, Larsen PR, Refetoff S, Stanbury B (1984) The thyroid and its diseases. New York: Wiley.

Diano S, Naftolin F, Goglia F, Horvath TL (1998) Fasting-induced increase in type II iodothyronine deiodinase activity and messenger ribonucleic acid levels is not reversed by thyroxine in the rat hypothalamus. Endocrinology 139:2879-2884.

Farwell AP, Lynch RM, Okuliez WC, Comi AM, Leonard JL (1990) The actin cytoskeleton mediates the hormonally regulated translocation of type II iodothyronine $5^{\prime}$-deiodinase in astrocytes. J Biol Chem 265:18546-18553.

Flament-Durand J, Brion JP (1985) Tanycytes: morphology and functions: a review. Int Rev Cytol 96:121-155.

Forrest D (1996) Deafness and goiter: molecular genetic considerations. Endocrinology 81:2764-2767.

Forrest D, Erway LC, Ng L, Altschuler R, Curran T (1996) Thyroid hormone receptor $\beta$ is essential for development of auditory function. Nat Genet 13:354-357.

Garcia-Segura LM, Cañas B, Parducz A, Rougon G, Theodosis D, Naftolin F, Torres-Aleman I (1995) Estradiol promotion of changes in the morphology of astroglia growing in culture depends on the expression of polysialic acid on neuronal membranes. Glia 13:209-216.

Guadaño-Ferraz A, Escámez M J, Morte B, Vargiu P, Bernal J (1997a) Transcriptional induction of $\mathrm{RC} 3 /$ neurogranin by thyroid hormone: differential neuronal sensitivity is not correlated with thyroid hormone receptor distribution in the brain. Mol Brain Res 49:37-44.

Guadaño-Ferraz A, Obregón M J, St. Germain D L, Bernal J (1997b)
The type 2 iodothyronine deiodinase is expressed primarily in glial cells in the neonatal rat brain. Proc Natl Acad Sci USA 94:10391-10396.

Iñiguez MA, De Lecea L, Guadaño-Ferraz A, Morte B, Gerendasy DD, Sutcliffe JG, Bernal J (1996) Cell-specific effects of thyroid hormone on RC3/Neurogranin expression in rat brain. Endocrinology 137: 1032-1041.

Jones EG (1985) The thalamus. New York: Plenum.

Kaplan MM, Yaskoski KA (1981) Maturational patterns of iodothyronine phenolic and tyrosyl ring deiodinase activities in rat cerebrum, cerebellum and hypothalamus. J Clin Invest 67:1208-1214.

Legrand J (1984) Effects of thyroid hormones on central nervous system (Yanay J, ed), pp 331-363. Amsterdam: Elsevier Science.

Leonard JL, Farwell AP, Yen PM, Chin WW, Stula M (1994) Differential expression of thyroid hormone receptor isoforms in neurons and astroglial cells. Endocrinology 135:548-555.

Lucio RA, García JV, Cerezo JR, Pacheco P, Innocenti GM, Berbel P (1997) The development of auditory callosal connections in normal and hypothyroid rats. Cereb Cortex 7:303-316.

Mellström B, Naranjo JR, Santos A, González AM, Bernal J (1991) Independent expression of the $\alpha$ and $\beta$ c-erba genes in developing rat brain. Mol Endocrinol 5:1339-1350.

Muñoz A, Bernal J (1997) Biological activities of thyroid hormones receptors. Eur J Endocrinol 137:433-445.

Obregón MJ, Ruiz de Oña C, Calvo R, Escobar Del Rey F, Morreale De Escobar G (1991) Outer ring iodothyronine deiodinases and thyroid hormone economy: responses to iodine deficiency in the rat fetus and neonate. Endocrinology 129:2663-2673.

Oppenheimer JH, Schwartz HL (1997) Molecular basis of thyroid hormone-dependent brain development. Endocr Rev 18:462-475.

Porterfield SP, Hendrich CE (1993) The role of thyroid hormones in prenatal and neonatal neurological development. Current perspectives. Endocr Rev 14:94-106.

Puymirat J, Miehe M, Marchand R, Sarlieve L, Dussault JH (1991) Immunocytochemical localization of thyroid hormone receptors in the adult rat brain. Thyroid 1:173-184.

Ruiz-Marcos A, Salas J, Sánchez-Toscano F, Escobar del Rey F, Morreale de Escobar G (1983) Effects of neonatal and adult onset hypothyroidism on pyramidal cells of the rat auditory cortex. Dev Brain Res 9:205-213.

Silva JE, Mathews P (1984) Thyroid hormone metabolism and the source of the plasma triiodothyronine in 2-week-old rats: effects of thyroid status. Endocrinology 114:2394-2405.

Silva JE, Gordon MB, Crantz FR, Leonard JL, Larsen PR (1984) Qualitative and quantitative differences in the pathways of extrathyroidal triiodothyronine generation between euthyroid and hypothyroid rats. J Clin Invest 73:898-907.

Snedecor GW, Cochran WG (1980) Statistical methods. Ames, IA: Iowa State UP.

St. Germain DL (1994) Iodothyronine deiodinases. Trends Endocrinol Metab 5:36-42.

St. Germain DL, Galton VA (1997) The deiodinase family of selenoproteins. Thyroid 7:655-668.

Swanson LW (1992) Brain maps: structure of the rat brain. Amsterdam: Elsevier Science.

Takeda K, Sakurai A, DeGroot LJ, Refetoff S (1992) Recessive inheritance of thyroid hormone resistance caused by complete deletion of the protein-coding region of the thyroid hormone receptor- $\beta$ gene. J Clin Endocrinol Metab 74:49-55.

Tu HM, Kim SW, Salvatore D, Bartha T, Legradi G, Larsen PR, Lechan RM (1997) Regional distribution of type 2 thyroxine deiodinase messenger ribonucleic acid in rat hypothalamus and pituitary and its regulation by thyroid hormone. Endocrinology 138:3359-3368.

van Doorn J, Roelfsema F, van der Heide D (1982) Contribution from local conversion of thyroxine to 3,5,3'-triiodothyronine to intracellular $3,5,3^{\prime}$-triiodothyronine in several organs in hypothyroid rats at isotope equilibrium. Acta Endocrinol 101:386-396.

Waite PME, Tracey DJ (1995) Trigeminal sensory system. In: The rat nervous system (Paxinos G, ed), pp 705-724. San Diego: Academic.

Yokota T, Nakamura H, Akamizu T, Mori T, Imura H (1986) Thyroid hormone receptors in neuronal and glial nuclei from mature rat brain. Endocrinology 118:1770-1776. 